\title{
ARPP-19 Mediates Herceptin Resistance via Regulation of CD44 in Gastric Cancer
}

This article was published in the following Dove Press journal: OncoTargets and Therapy

\author{
Xiang Gao (iD ${ }^{1, *}$ \\ Changwen Lu'** \\ Changyu Chen $\mathbb{D}^{2}$ \\ Kang Sun' \\ Qixin Liang $\mathbb{D}^{\prime}$ \\ Jianfeng Shuai' \\ Xiaoming Wang' \\ Yuxing $\mathrm{Xu}\left(\mathbb{D}^{\prime}\right.$ \\ 'Department of General Surgery, The \\ First Affiliated Hospital of Anhui \\ University of Chinese Medicine, Hefei, \\ People's Republic of China; ${ }^{2}$ Department \\ of Gastrointestinal Surgery, The First \\ Affiliated Hospital of Nanchang \\ University, Nanchang, People's Republic \\ of China
}

*These authors contributed equally to this work
Correspondence: Yuxing $\mathrm{Xu}$

Department of General Surgery, The First Affiliated Hospital of Anhui University of Chinese Medicine, 117 Meishan Avenue, Hefei 23003I, Anhui, People's Republic of China

Tel +86 I38-5699-6478

Email blackbird007@163.com
Purpose: As the first-line drug for treatment of HER2-positive metastatic gastric cancer (GC), Herceptin exhibits significant therapeutic efficacy. However, acquired resistance of Herceptin limits the therapeutic benefit of gastric cancer patients, in which the molecular mechanisms remain to be further determined.

Methods: Quantitative real-time polymerase chain reaction was performed to detect the mRNA levels of ARPP-19 and CD44 in GC cells. Protein levels were determined using Western blot and IHC staining. MTT and soft agar colony formation assays were used to measure cell proliferation. Xenograft model was established to verify the functional role of ARPP-19 in Herceptin resistance in vivo. Sphere formation assay was conducted to determine cell stemness.

Results: We observed $A R P P-19$ was up-regulated in Herceptin resistance gastric cancer cells NCI-N87-HR and MKN45-HR. The forced expression of ARPP-19 promoted, whereas the silencing of ARPP-19 impaired Herceptin resistance of HER2-positive gastric cancer cells both in vitro and in vivo. Moreover, ARPP-19 significantly enhanced the sphere formation capacity and CD44 expression, $C D 44$ was also a positive factor of Herceptin resistance in HER2positive gastric cancer cells. In addition, high level of $A R P P-19$ was positively associated with Herceptin resistance and poor survival rate of gastric cancer patients.

Conclusion: We have demonstrated that $A R P P-19$ promoted Herceptin resistance of gastric cancer via up-regulation of $C D 44$, our study suggested that $A R P P-19$ could be a potential diagnostic and therapeutic candidate for HER2-positive gastric cancer.

Keywords: Herceptin resistance, HER2, gastric cancer, ARPP-19, CD44

\section{Introduction}

Gastric cancer (GC) is one of the most commonly diagnosed malignancies and contributes to the third leading cancer-specific mortality worldwide. ${ }^{1}$ Although notable progress in GC diagnosis and treatment has been achieved, the prognosis of patients with recurrent or metastatic GC remains much unsatisfactory due to the high cancer heterogeneity. ${ }^{2,3}$ Human epidermal growth factor receptor 2 (HER2), whose expression dysregulated in as many as $7-34 \%$ of $\mathrm{GC}^{4-6}$ is a $185 \mathrm{kDa}$ transmembrane tyrosine kinase receptor. ${ }^{7}$ Herceptin (the only monoclonal humanized antibody targeting at HER2 approved by the FDA) has been demonstrated to significantly improve the clinical outcome of patients with HER2-positive gastric cancer in the ToGA trial. However, most patients developed Herceptin resistance after their one-year initial response.

Increasing studies have reported that the complicated molecular mechanisms of Herceptin resistance in $\mathrm{GC}$, with the involvement of some crucial molecules and signal pathway. Shi et al reported the HER4-YAPl axis promotes Herceptin 
resistance in HER2-positive gastric cancer by inducing epithelial and mesenchymal transition. ${ }^{8}$ The sensitivity of gastric cancer to Herceptin is regulated by the $m i R$ 223/FBXW7 pathway. ${ }^{9}$ Tang et al demonstrated that NES1/KLK10 promotes Herceptin resistance via activation of $P I 3 K / A K T$ signaling pathway in gastric cancer. ${ }^{10}$ Nevertheless, the diverse and deep molecular mechanisms of Herceptin resistance in GC are still urgent to be characterized to provide diagnosis and treatment strategies for patients suffering from inevitable resistance.

ARPP-19 (cAMP-regulated phosphoprotein 19) is a member of the alpha-endosulfine (ENSA) family and characterized as a substrate for protein kinase $\mathrm{A}$ in mammalian brain. ${ }^{11,12}$ ARPP-19 is ubiquitously expressed and its related proteins have also been identified in Caenorhabditis elegans, Schistosoma mansoni, Drosophila melanogaster and yeast genomes. ${ }^{12,13}$ In the neuronal system, ARPP-19 links the nerve growth factor signaling to the post-transcriptional regulation of neuronal gene expression to promote the growth of synapses and synaptic plasticity. ${ }^{14}$ ARPP-19 has also been reported to play a pivotal role in the pathogenesis of neuronal system diseases, such as Down syndrome and Alzheimer's disease. ${ }^{15}$ Furthermore, ARPP-19 has been demonstrated to act as an oncogene in tumorigenesis and progression. For example, it has been reported that $A R P P-19$ promotes proliferation and metastasis of human glioma; ${ }^{16} A R P P-19$ has also been reported to be targeted by microRNA-320a and mediate tamoxifen resistance of breast cancer cells; in addition, increased ARPP-19 expression is associated with hepatocellular carcinoma. $^{17}$ However, the functions and underlying mechanisms of ARPP-19 in Herceptin resistance of HER2-positive gastric cancer cells have been rarely explored.

In the present study, ARPP-19 was observed to be remarkably up-regulated in GC cells and tissues with Herceptin resistance. We also demonstrated that ARPP19 enhanced Herceptin resistance of HER2-positive GC cells both in vitro and in vivo. Besides, $C D 44$ was positively regulated by $A R P P-19$ and silence of $C D 44$ resensitized Herceptin resistant GC cells to Herceptin. Furthermore, elevated ARPP-19 predicted poorer overall survival rate of GC patients. Therefore, these results help throw light upon the complicated mechanisms of Herceptin resistance and $A R P P-19$ may be used as a new prognosis bio-marker or therapeutic target in GC patients with Herceptin resistance.

\section{Materials and Methods Clinical Gastric Cancer Specimens}

Fifty paraffin-embedded HER2-positive (diagnosed as $H E R 2++$ or HER2+++ by immunohistochemistry in the department of pathology) gastric cancer tissues were collected at Department of General Surgery, the First Affiliated Hospital of Anhui Medical University between 2005 and 2015. The clinicopathological characteristics of these patients without any other diseases or special therapies were recorded according to World Health Organization (WHO) classification system. The follow-up time is from the diagnosis to mortality or the date last known alive. Moreover, all of these 50 patients were received Herceptin-based therapy and their prognosis was collected. Tissues from patients with good prognosis after Herceptin treatment were designated to be Herceptin sensitive, and tissues from patients with poor prognosis or with tumor recurrence shortly were designated to be Herceptin resistant. Informed consent was signed by each patient enrolled. The study protocol about the clinical samples has been reviewed and approved by the ethics committee of the First Affiliated Hospital of Anhui Medical University in accordance with the Code of Ethics of the World Medical Association (Declaration of Helsinki).

\section{Cell Lines and Cell Culture}

Two human HER2-positive GC cell lines (NCI-N87 and MKN45) were purchased from ATCC. All cell lines were cultured in RPMI 1640 (Hyclone) supplemented with 10\% fetal bovine serum (FBS, Gibco-BRL; Invitrogen) and incubated at $37^{\circ} \mathrm{C}$ in a humidified chamber containing $5 \%$ $\mathrm{CO}_{2}$.

Herceptin resistant GC cell lines (NCI-N87-HR and MKN45-HR) were established as described previously. ${ }^{18}$ Briefly, the parental NCI-N87 and MKN45 cells were treated with increasing doses of Herceptin gradually for 6 months until Herceptin resistance was stably acquired. NCI-N87-HR and MKN45-HR cells were normally maintained with $10 \mu \mathrm{g} / \mathrm{mL}$ Herceptin.

\section{RNA Extraction and qRT-PCR Analysis}

Total RNA from cells was isolated by using Trizol (Invitrogen, Carlsbad, CA) and converted to cDNA using RevertAid First Strand cDNA Synthesis Kit (Thermo Scientific Bio) following the manufacturer's instructions. qRT-PCR analysis was performed by SYBR green Master MIX (Applied Biosystem) as 
recommended. ${ }^{19,20} G A P D H$ was used as an internal control to normalized the mRNA expression. Sequences of all the primers used are listed in Table 1.

\section{Plasmid Constructs and Transfection}

Human ARPP-19 coding sequence transcript (Gene ID: 10776) was cloned and inserted into mammalian expression vector pIRESneo3 (Invitrogen). Lipofectamine 2000 (QIAGEN) was used for plasmid transfection as described previously. $^{10,16}$

\section{RNA Oligonucleotides and Transfection} siRNAs against ARPP-19 and CD44 were designed and synthesized by GenePharma (Shanghai, China). The sequences of siRNAs used in this study are listed in Table 1. siRNAs transfection was performed by using Lipofectamine 2000 (QIAGEN) according to the manufacturer's instructions as recommended. ${ }^{21,22}$

\section{Protein Extraction and Western Blot}

Cells were lysed in modified RIPA buffer and total protein was extracted according to the manufacturer's instructions. Western blot was conducted as previously described. ${ }^{17,23}$ The primary antibodies against ARPP-19 (11678-1-AP) and $C D 44$ (3570) were purchased from Proteintech and Cell Signaling Technology, respectively. Anti- $\beta$-actin antibody (sc-47778, Santa Cruz Biotechnology, USA) was used as a protein loading control.

\section{Immunohistochemical Staining}

The UltraSensitive-SP kit (Maxin-Bio, Fuzhou, China) was used to conduct immunohistochemistry (IHC) analysis. All steps were performed strictly according to the kit's instructions. Protein levels of ARPP-19 in the paraffinembedded HER2-positive gastric cancer tissues were

Table I Oligomers Used in This Study

\begin{tabular}{|l|l|l|}
\hline Name & Application & Sequence \\
\hline qRT-ARPP-19-F & qRT-PCR & GCCTGGAGGTTCAGATTT \\
qRT-ARPP-19-R & qRT-PCR & CAGTAGGAAGTTGCTTGTTC \\
qRT-CD44-F & qRT-PCR & TCAGTCACAGACCTGC CCAA \\
qRT- CD44-R & qRT-PCR & CCTTTCTGGACATAGCGGGT \\
qRT-GAPDH-F & qRT-PCR & AGAAGGCTGGGGCTCATTTG \\
qRT-GAPDH-R & qRT-PCR & AGGGGCCATCCACAGTCTTC \\
siARPP-19-I & Transfection & GAAATGGAAGATAAAGTGACT \\
siARPP-19-2 & Transfection & ATGAAGAACAAGCAACTTCCT \\
siCD44-I & Transfection & GCAGCACTTCAGGAGGTTACA \\
siCD44-2 & Transfection & GGATGACTGATGTAGACAGAA \\
\hline
\end{tabular}

detected by using the rabbit polyclonal antibody against ARPP-19 (1:200, 11678-1-AP, Proteintech, Wuhan, China), and rabbit polyclonal antibody against CD44 (1:200, 15675-1-AP, Proteintech, Wuhan, China) was used to detect $C D 44$. Sections with $\geq 15 \%$ stained cells were considered to be $A R P P-19 / C D 44$ high expression, and sections with $<15 \%$ stained cells were considered to be $A R P P-19 / C D 44$ low expression.

\section{MTT Assays}

Logarithmically growing cells $\left(5.0 \times 10^{3}\right.$ cells/well $)$ were seeded in the 96-well plates and treated with the indicated concentrations of Herceptin for 6 days. MTT reagent (Promega) was added into each well and the absorbance at $570 \mathrm{~nm}$ was measured after 2 hours of incubation.

\section{Soft Agar Colony Formation Assay}

Soft agar colony formation assay was performed as described earlier. ${ }^{24,25}$ In brief, $48 \mathrm{~h}$ after the indicated transfection, cells were digested and resuspended with $0.3 \%$ soft agar in RPMI-1640 containing 10\% FBS. Three hundred cells were seeded in the six-well plate per well, and coated with $0.6 \%$ solidified agar in RPMI-1640 containing 10\% FBS. Media were refreshed every 3 days. About two weeks later, cells were fixed with methanol for $10 \mathrm{~min}$ at $-20^{\circ} \mathrm{C}$ and stained with $0.005 \%$ crystal violet (Sigma-Aldrich Co., St Louis, MO, USA) for $10 \mathrm{~min}$ at room temperature. The colonies were counted for statistical analysis.

\section{Sphere Formation Assays}

Cells $\left(10^{5}\right)$ suspended in the serum-free DMEM medium containing 0.4\% BSA (Sigma), 2\% B27 (BD Pharmingen), $5 \mu \mathrm{g} / \mathrm{mL}$ insulin (Sigma), $20 \mathrm{ng} / \mathrm{mL}$ basic fibroblast growth factor (bFGF, Invitrogen) and $20 \mathrm{ng} / \mathrm{mL}$ epidermal growth factor ( $E G F$, Invitrogen) were plated in the sixwell ultra-low attachment plates (Corning). Two weeks later, images of the spheres were taken in three randomly chosen fields with the microscope (Nikon) and NISElement F3.0 program (Nikon) and the numbers of spheres in each field were counted for statistical analysis.

\section{Xenograft and Ki-67 Staining}

For animal experiments, all procedures were reviewed and approved by the Animal Study Committee of the First Affiliated Hospital of Anhui Medical University in Hefei, Anhui Province, China, and in compliance with the 
National Institutes of Health (NIH) Guide for the Care and Use of Laboratory Animals and Animal Welfare Act. MKN45 Vec and MKN45 ARPP-19 cells $\left(5 \times 10^{6}\right.$ per $125 \mu \mathrm{L}$ per site) were injected subcutaneously into the right flanks of 5 week-old nude female mice (12 mice each cells). Mice injected with MKN45 Vec or MKN45 ARPP-19 cells were randomized to receive Herceptin $(10 \mathrm{mg} / \mathrm{kg})$ or vehicle as control (6 mice each group) by tail vein injection once a week after the palpable tumors were formed, respectively. Tumor growth was recorded by measuring the length (L) and width (W) and tumor volume was calculated using the formula: Volume $(\mathrm{mm} 3)=\mathrm{L} x$ $\mathrm{W}^{2} \times \Pi / 6^{8}$.

Mice were sacrificed and tumors were resected after 39 days. Ki-67 staining was performed to assess the tumor cell viability of the harvested tumor tissues and the percentage of Ki-67 positive cell population was calculated.

\section{Statistical Analysis}

All the experiments were repeated at least three times. Student's $t$-test was used to analyze the difference between the two groups; chi-squared test was used to analyze expression of ARPP-19 in HER2-positive gastric cancer tissues; Kaplan-Meier's analysis was used for prognostic analyses. All statistical analyses were performed using GraphPad Prism (San Diego, CA) and $P<0.05$ was considered as statistically significant.

\section{Results}

The Expression of ARPP-19 Was Elevated in Human HER2-Positive Gastric Cancer Cells with Herceptin Resistance

To evaluate the expression pattern of ARPP-19 in human HER2-positive gastric cancer cells with Herceptin resistance, we first established two human HER2-positive Herceptin resistant GC cell lines: NCI-N87-HR and MKN45-HR. We found both NCI-N87-HR and MKN45HR cells exhibited remarkable resistance to Herceptin, compared to their parental NCI-N87 and MKN45 cells (Figure 1A). Subsequently, the expression levels of ARPP-19 in NCI-N87-HR and MKN45-HR cells and their parental cells were determined by qRT-PCR and Western blot. Both the mRNA (Figure 1B) and protein (Figure 1C) levels of ARPP-19 were obviously upregulated in NCI-N87-HR and MKN45-HR cells compared with NCI-N87 and MKN45 cells, respectively.
Thereby, ARPP-19 was over-expressed in GC cells with acquired Herceptin resistance.

\section{Silence of ARPP-I 9 Sensitized Acquired Herceptin Resistant Gastric Cancer Cells to Herceptin}

We further explored the detailed role of ARPP-19 in Herceptin resistance of GC cells. The specific siRNAs against ARPP-19 were transfected into NCI-N87-HR and MKN45-HR cells, siARPP-19 significantly silenced the protein levels of ARPP-19 compared with siNC in NCIN87-HR and MKN45-HR cells (Figure 2A). Cell viability of NCI-N87-HR and MKN45-HR transfected with siNC showed no significant difference when treated with Herceptin compared with vehicle control. However, depleted ARPP-19 expression led to significantly reduced cell viability with the treatment of Herceptin compared with vehicle control (Figure 2B). The fold change of vehicle-treated group compared with Herceptin treated group was $0.98(P>0.05)$ in NCI-N87-HR-siNC cells, $1.38(P<0.05)$ in NCI-N87-HR-siARPP-19 cells, 1.04 $(P>0.05)$ in MKN45-HR-siNC cells, and $1.47(P<0.05)$ in MKN45-HR-siARPP-19 cells (Figure 2B). Besides, as showed in Figure 2C, siRNA-mediated depletion of ARPP-19 decreased cell colony formation in soft agar on exposure to Herceptin in NCI-N87-HR and MKN45-HR cells, with the fold change of vehicle/Herceptin: NCI-N87HR-siNC $1.01 \quad(P>0.05)$, NCI-N87-HR-siARPP-19 1.41 $(P<0.05)$, MKN45-HR-siNC $1.05(P>0.05)$ and MKN45HR-siARPP-19 $1.52 \quad(P<0.05)$. Taken together, these results suggested that silence of $A R P P-19$ significantly resensitized Herceptin resistant cells NCI-N87-HR and MKN45-HR to Herceptin.

\section{ARPP-19 Promoted Resistance to Herceptin of Gastric Cancer Cells Both} in vitro and in vivo

Further on, NCI-N87 and MKN45 cells were stably transfected with ARPP-19 overexpression plasmid or the empty vector, the overexpression efficacy was confirmed by Western blot (Figure 3A). Results in Figure $3 \mathrm{~B}$ and $\mathrm{C}$ showed cell viability and cell colony formative capacity in soft agar of NCI-N87 and MKN45 cells increased after transfection with ARPP-19 overexpression plasmid compared with Vector control. Treatment with Herceptin dramatically reduced cell viability and cell colony formative capacity in soft agar of NCI-N87 
A
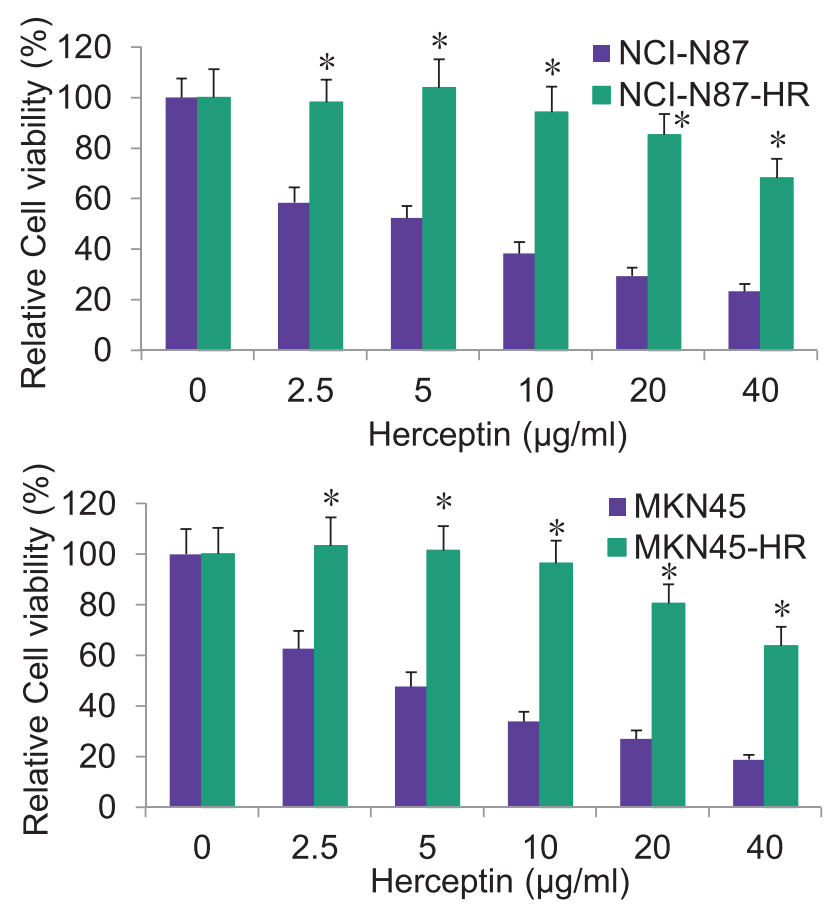

B
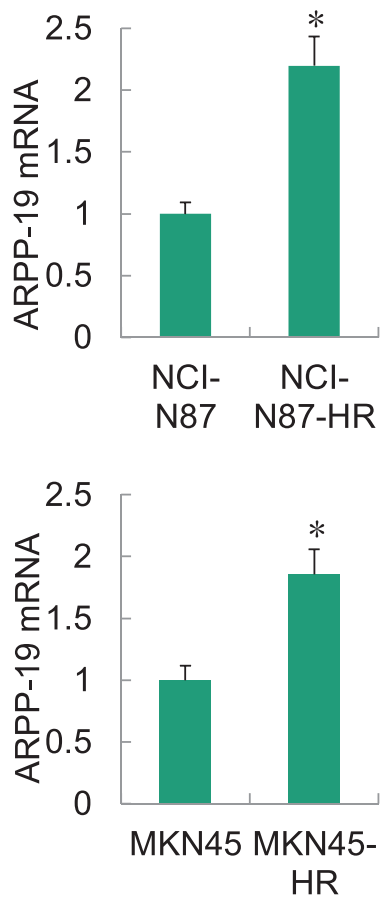

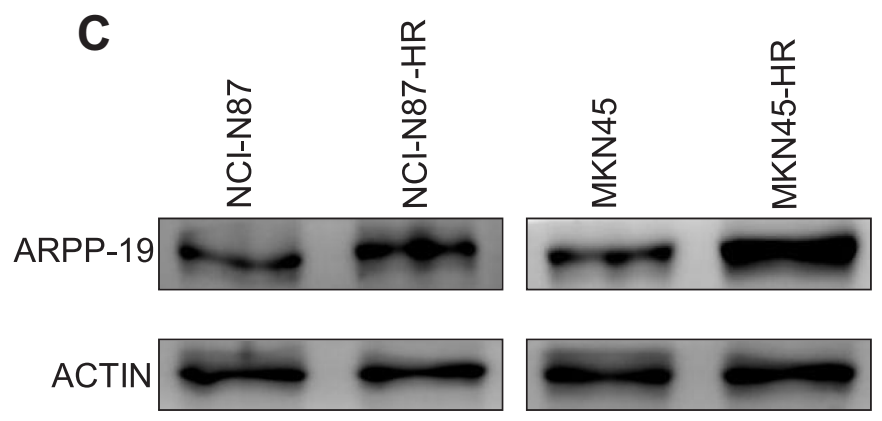

Figure I Expression of ARPP-19 was elevated in HER2-positive gastric cancer with acquired Herceptin resistance. (A) MTT assay was performed to detect cell viability of Herceptin resistant cells NCl-N87-HR and MKN45-HR or their parental cells NCl-N87 and MKN45 after the treatment with the indicated concentrations of Herceptin for 6 days. (B) qRT-PCR analysis of ARPP-19 mRNA level in NCI-N87-HR and MKN45-HR cells or their corresponding parental cells. (C) Western blot was conducted to examine the protein level of ARPP-19 in NCI-N87-HR and MKN45-HR cells or their corresponding parental cells. $* P<0.05$.

Vec and MKN45 Vec cells, while NCI-N87 and MKN45 cells with overexpression of ARPP-19 exhibited less significant inhibitory effects on cell viability and cell colony formative capacity in soft agar with treatment of Herceptin (Fold change of vehicle/Herceptin for cell viability: NCI-N87 Vec $2.48 \quad(P<0.05), \quad$ NCI-N87 $A R P P-191.81 \quad(P<0.05)$, MKN45 Vec $2.83 \quad(P<0.05)$ and MKN45 ARPP-19 $1.73(P<0.05)$. Fold change of vehicle/Herceptin for cell colony formative capacity in soft agar: NCI-N87 Vec $2.16(P<0.05)$, NCI-N87 ARPP$191.77 \quad(P<0.05)$, MKN45 Vec $2.32 \quad(P<0.05)$ and MKN45 ARPP-19 $1.76 \quad(P<0.05))$. Therefore, forced expression of ARPP-19 decreased the sensitivity of NCI-N87 and MKN45 cells to Herceptin in vitro.

To determine the role of ARPP-19 in Herceptin sensitivity of gastric cancer in vivo. MKN45 ARPP-19 and MKN45 Vec cells were injected subcutaneously into the right flanks of 5-week-old female BALB/c nude mice. Mice injected with these two group of cells were, respectively, randomized to receive either Herceptin or vehicle as control when the palpable tumors were formed. Tumor sizes were measured every 5 days and tumor growth curves were analyzed at the 40th day. Tumors derived from MKN45 ARPP-19 cells grew much faster, resulting in mean tumor volume and 


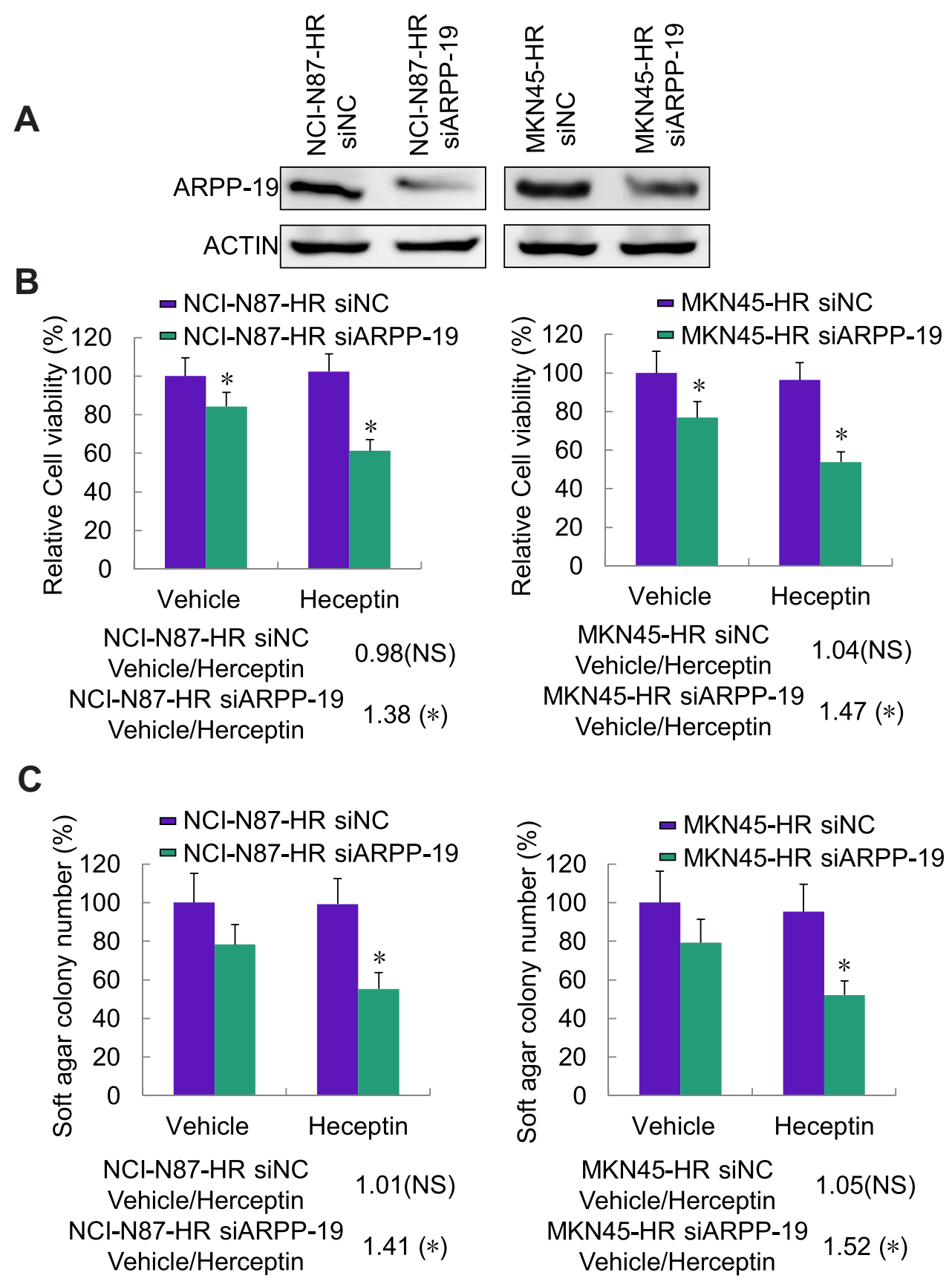

Figure 2 Knockdown of ARPP-19 re-sensitized NCI-N87-HR and MKN45-HR cells to Herceptin. (A) Protein level of ARPP-19 in NCI-N87-HR and MKN45-HR cells transfected with siRNAs against ARPP-19 (siARPP-19) or negative control siRNA (siNC) was determined by Western blot. (B) NCI-N87-HR and MKN45-HR cells transfected with siRNAs against ARPP-19 (siARPP-19) or negative control siRNA (siNC) were treated with Herceptin (I0 $\mu \mathrm{g} / \mathrm{mL})$ or vehicle for 6 days; cell viability was determined by MTT assay. (C) NCI-N87-HR and MKN45-HR cells transfected with siRNAs against ARPP-19 (siARPP-19) or negative control siRNA (siNC) were treated with Herceptin (I0 $\mu \mathrm{g} / \mathrm{mL}$ ) or vehicle for 6 days; cell colony formation in soft agar was examined. $* P<0.05$.

weight approximately two-fold of those of tumors derived from MKN45 Vec cells. Treatment with Herceptin decreased both MKN45 ARPP-19 cells-derived and MKN45 Vec cellsderived tumor volume and weight, but MKN45 ARPP-19 cells-derived tumors showed dramatically less decrease on exposure to Herceptin with a growth curve similar with MKN45 Vec cells without the treatment of Herceptin
(Figure 4A and B). At day 40, mice were sacrificed and the resected tumors were made into paraffin sections for $\mathrm{Ki}$ 67 staining analysis. In consistence with tumor volume and weight, $\mathrm{Ki}-67$ positive cell population in MKN45 ARPP-19 cells-derived tumors was significantly higher than the tumors formed by MKN45 Vec cells. Herceptin reduced Ki-67 positivity in both MKN45 ARPP-19 cells-derived 


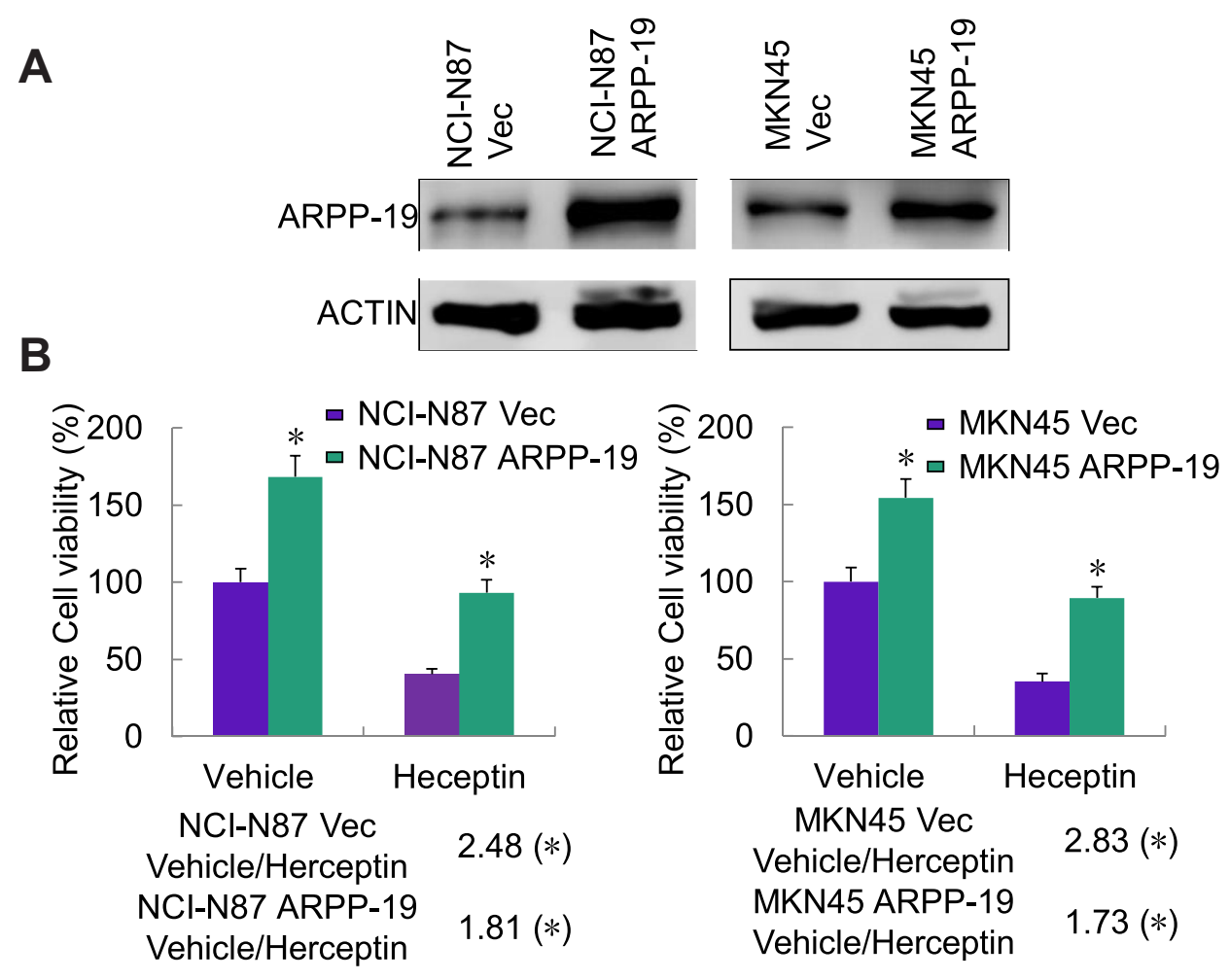

C
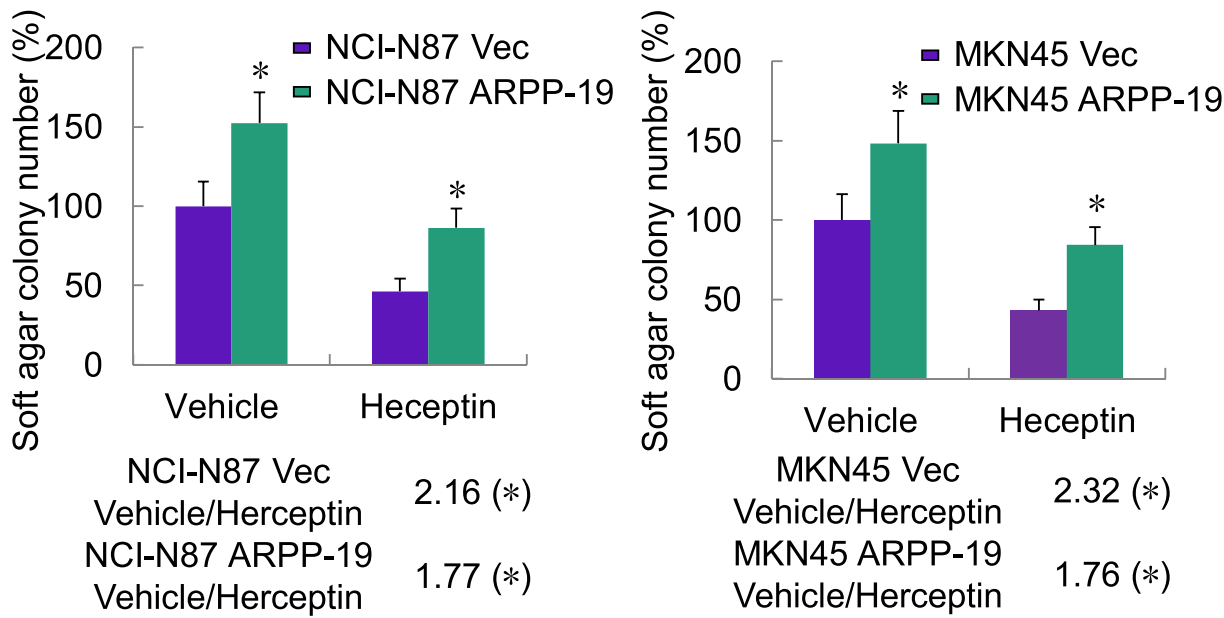

Figure 3 Overexpression of ARPP-19 decreased Herceptin sensitivity of NCl-N87 and MKN45 cells in vitro. (A) Protein level of ARPP-19 in NCI-N87 and MKN45 cells stably transfected with ARPP-19 overexpression plasmid (NCI-N87/MKN45 ARPP-19) or empty vector (NCl-N87/MKN45 Vec) was determined by Western blot. (B) NCl$\mathrm{N} 87$ and MKN45 cells stably transfected with ARPP-19 overexpression plasmid (NCI-N87/MKN45 ARPP-19) or empty vector (NCI-N87/MKN45 Vec) were treated with Herceptin $(2.5 \mu \mathrm{g} / \mathrm{mL})$ or vehicle for 6 days; cell viability was determined by MTT assay. (C) NCl-N87 and MKN45 cells stably transfected with ARPP-19 overexpression plasmid (NCI-N87/MKN45 ARPP-19) or empty vector (NCI-N87/MKN45 Vec) were treated with Herceptin (2.5 $\mu$ g/mL) or vehicle for $6 \mathrm{days}$; cell colony formation in soft agar was examined. $* P<0.05$.

and MKN45 Vec cells-derived tumors, whereas tumors formed by MKN45 ARPP-19 cells with the treatment of Herceptin maintained comparative $\mathrm{Ki}-67$ positivity with tumors derived from MKN45 Vec cells in the absence of Herceptin treatment (Figure 4C). Collectively, forced expression of ARPP-19 reduced sensitivity of gastric cancer cells to Herceptin in vivo.

\section{CD44 Was Regulated by ARPP-19 and Overexpressed in Herceptin Resistant Gastric Cancer Cells}

As reported previously, cancer stem cell (CSC) played a pivotal role in the acquired Herceptin resistance of gastric cancer, ${ }^{26}$ and $C D 44$ was an important factor contributed to cancer stem cell-like properties in gastric 


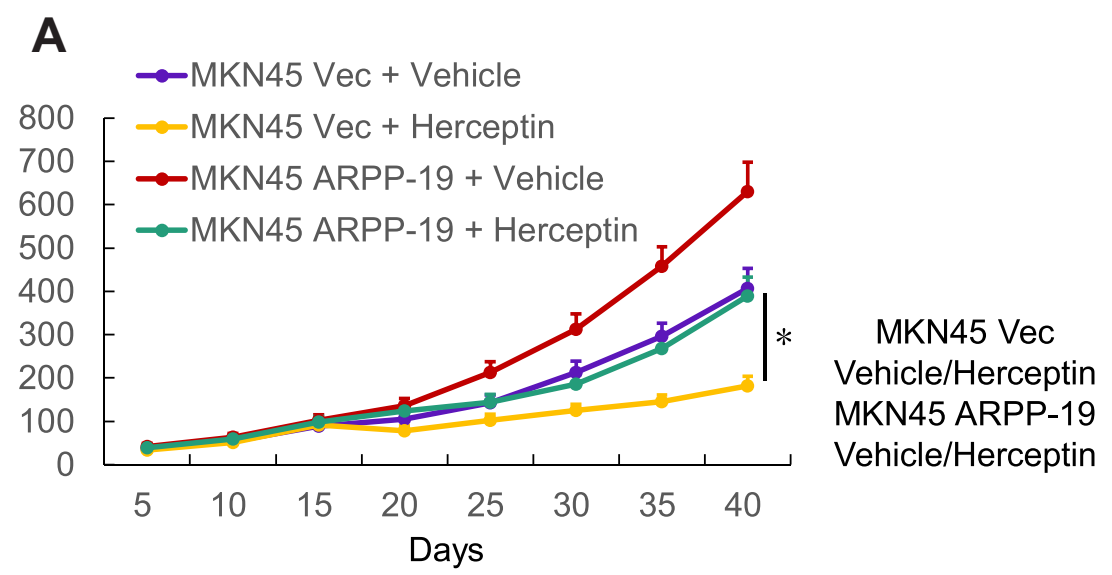

$2.23(*)$

$1.62(*)$
B

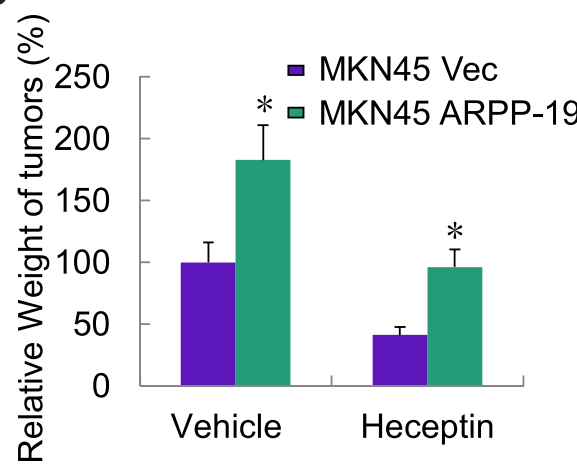

C

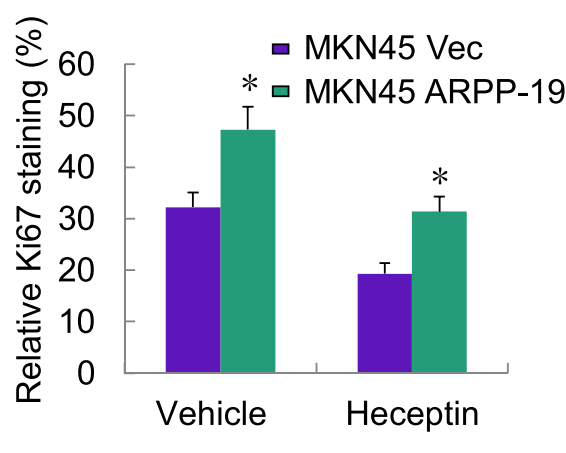

Figure 4 Forced expression of ARPP-19 decreased Herceptin sensitivity of MKN45 cells in xenograft model. (A) Tumor growth curves of MKN45 ARPP-19- or MKN45 Vecderived tumors of mice with the treatment of Herceptin $(10 \mathrm{mg} / \mathrm{kg})$ or vehicle. (B) Tumor weights of each group were measured after mice were sacrificed and tumors were resected at day 40 . (C) Ki-67 staining of tumor sections from mice of each group. $* P<0.05$.

cancer. $^{27,28}$ We examined the expression level of $C D 44$ in Herceptin resistance gastric cancer cells NCI-N87-HR and MKN45-HR with the silence of ARPP-19, the mRNA (Figure 5A and $\mathrm{B}$ ) and protein (Figure 5C) levels of CD44 obviously decreased in NCI-N87-HR and MKN45-HR cells transfected with siARPP-19 compared with siNC (another two cancer-stem-cell-related genes SOX2 and $c-M Y C$ were also determined, but they did not change significantly (data not shown)). Besides, the mRNA (Figure 5D and E) and protein (Figure 5F) levels of CD44 were significantly up-regulated in NCI-N87-HR and MKN45-HR cells compared to their parental cells.

\section{CD44-Mediated Herceptin Resistance of Gastric Cancer Cells}

To assess the role of CD44 played in acquired Herceptin resistant gastric cancer cells. We depleted the endogenous CD44 in NCI-N87-HR and MKN45-HR cells by transfection of specific siRNAs against $C D 44$, and the knockdown efficacy of CD44 was verified by Western blot (Figure 6A). Cell viability and cell colony formative capacity in soft agar of NCI-
N87-HR and MKN45-HR cells transfected with siCD44 or siNC and treated with Herceptin or vehicle were determined by MTT assay and soft agar colony formation assay, respectively. Similarly, we found cell viability and soft agar colony formation of NCI-N87-HR and MKN45-HR transfected with siNC showed no significant difference when treated with Herceptin compared with vehicle control. However, depleted CD44 expression led to significantly reduced cell viability and soft agar colony formation with the treatment of Herceptin compared with vehicle control (Figure 6B and C). Collectively, depletion of $C D 44$ re-sensitized the Herceptin resistant gastric cancer cells to Herceptin.

\section{ARPP-I 9 Promoted}

\section{Cancer-Stem-Cell-Like Properties in} Herceptin Resistant Gastric Cancer Cells As $C D 44$ was an important factor in gastric cancer stem cells and ARPP-19 positively regulated the expression of CD44 in Herceptin resistant gastric cancer cells, ARPP-19 might perform an important role in cancer-stem-cell-like properties of Herceptin resistant gastric cancer cells. 
A

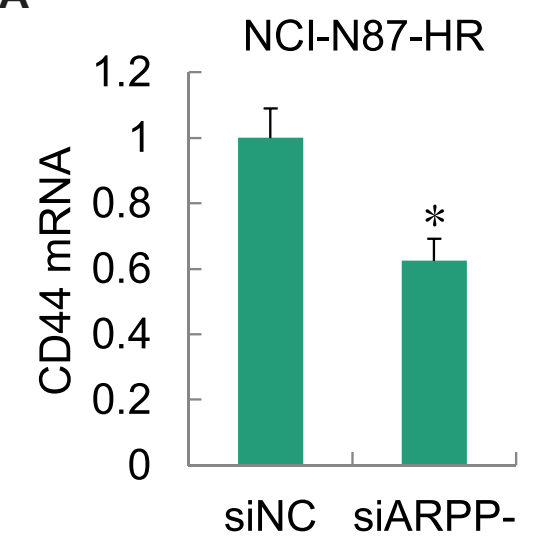

C

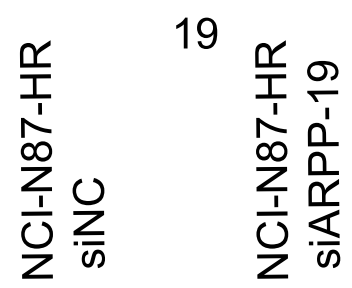

CD44

ACTIN
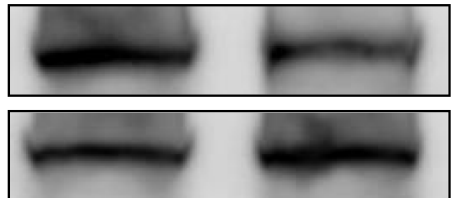

D

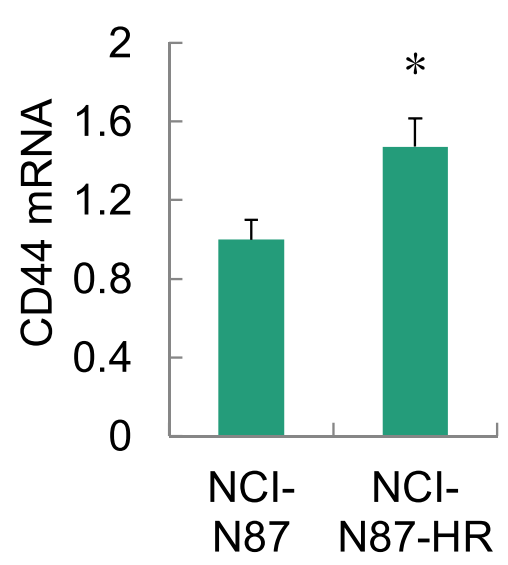

F

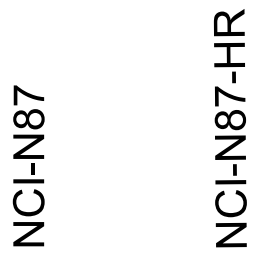

\section{CD44}

ACTIN
B
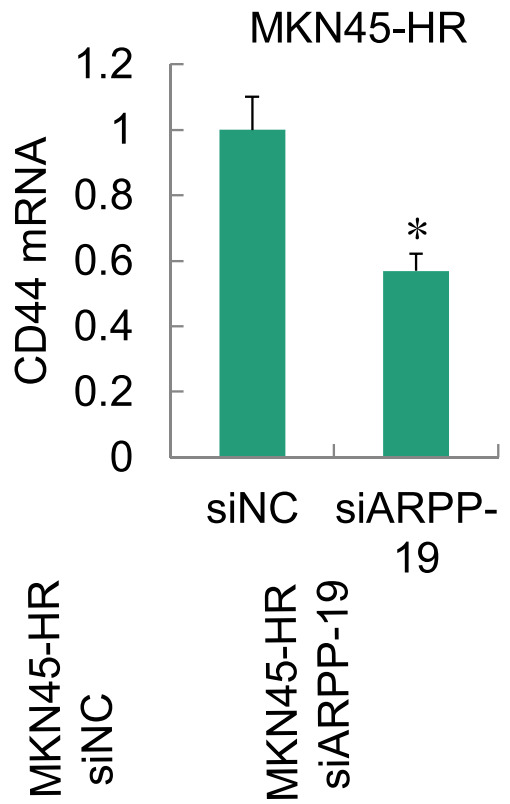

19

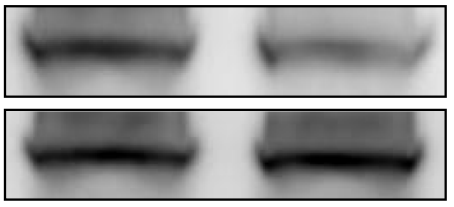

E
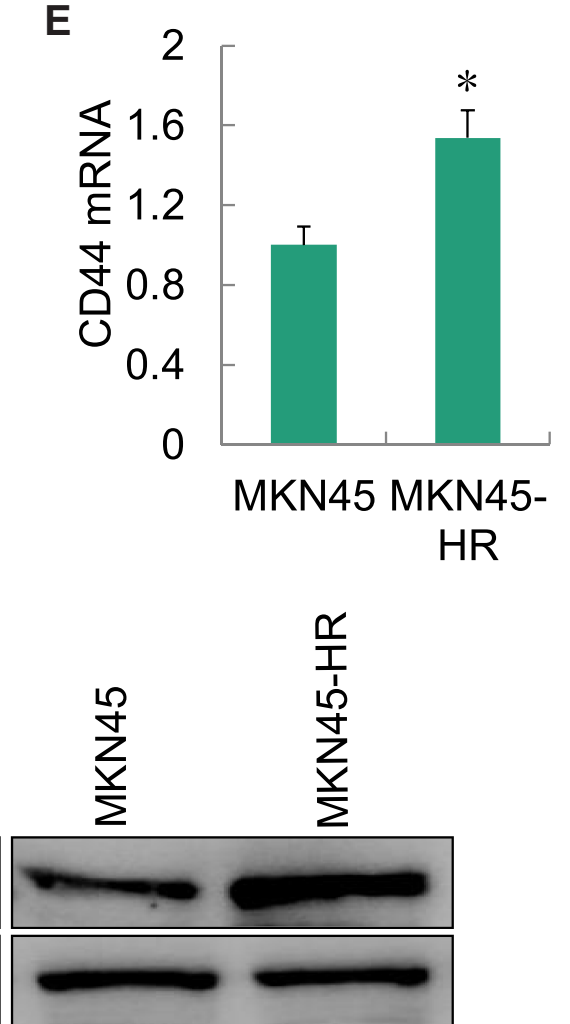

Figure 5 CD44 was regulated by ARPP-19 in NCl-N87-HR and MKN45-HR cells. (A and B) mRNA level of CD44 in NCI-N87-HR and MKN45-HR cells transfected with siRNAs against ARPP-19 (siARPP-19) or negative control siRNA (siNC) was determined by qRT-PCR. (C) Protein level of CD44 in NCl-N87-HR and MKN45-HR cells transfected with siRNAs against ARPP-19 (siARPP-19) or negative control siRNA (siNC) was determined by Western blot. (D and E) mRNA level of CD44 in NCI-N87-HR and MKN45-HR cells or their parental NCI-N87 and MKN45 cells was determined by qRT-PCR. (F) Protein level of CD44 in NCI-N87-HR and MKN45-HR cells or their parental NCl-N87 and MKN45 cells was determined by Western blot. $* P<0.05$. 


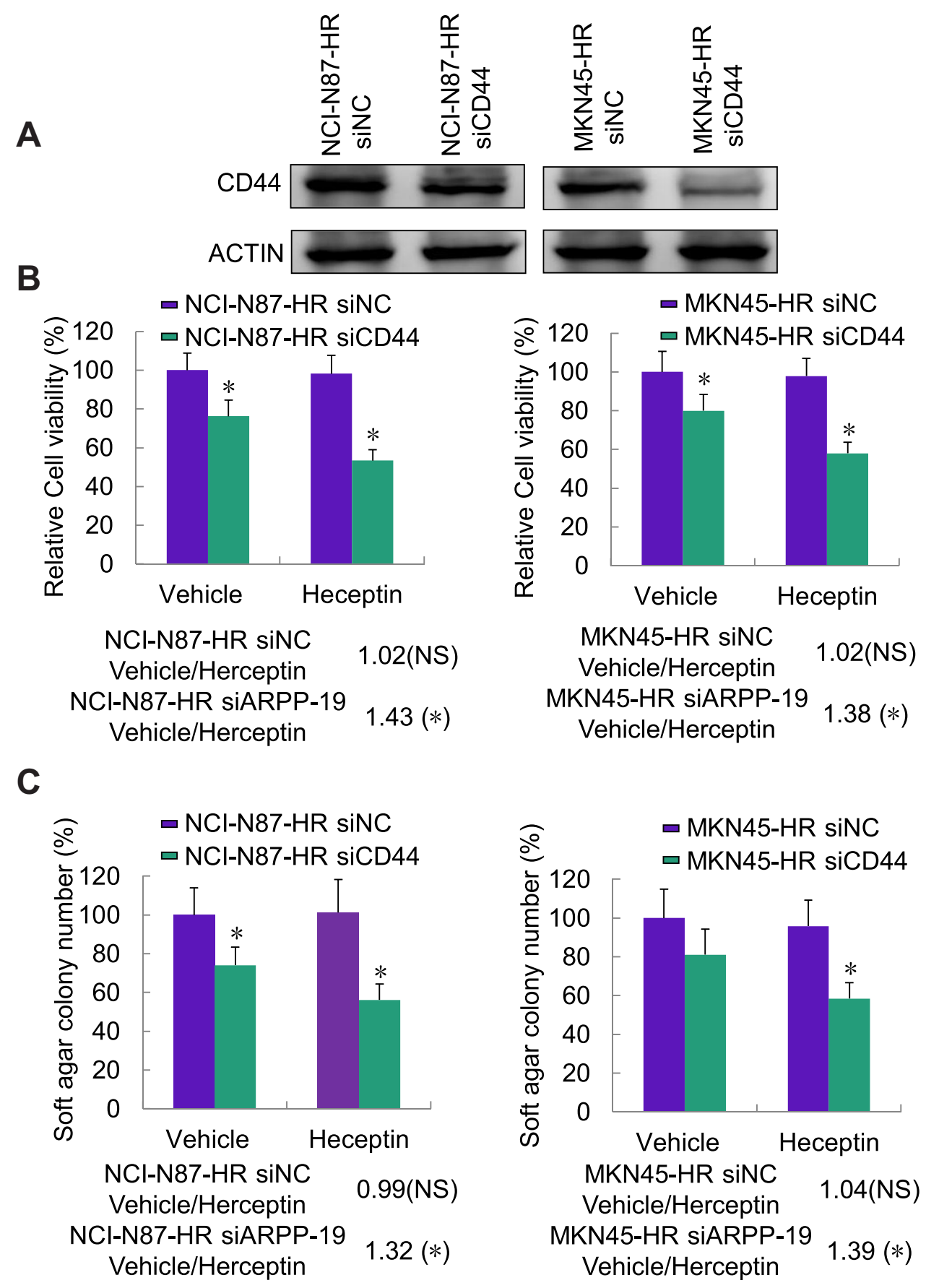

Figure 6 Depletion of CD44 reduced Herceptin resistance of NCI-N87-HR and MKN45-HR cells. (A) Protein level of CD44 in NCl-N87-HR and MKN45-HR cells transfected with siRNAs against CD44 (siCD44) or negative control siRNA (siNC) was determined by Western blot. (B) NCl-N87-HR and MKN45-HR cells transfected with siRNAs against CD44 (siCD44) or negative control siRNA (siNC) were treated with Herceptin $(10 \mu \mathrm{g} / \mathrm{mL})$ or vehicle for 6 days; cell viability was determined by MTT assay. (C) NCl-N87-HR and MKN45-HR cells transfected with siRNAs against CD44 (siCD44) or negative control siRNA (siNC) were treated with Herceptin (I0 $\mu$ g/mL) or vehicle for 6 days; cell colony formation in soft agar was examined. $* P<0.05$.

Concordantly, an enhanced sphere formation capacity was observed in NCI-N87-HR cells as compared to its parental NCI-N87 cells (Figure 7A). Forced expression of ARPP19 promoted sphere formation of NCI-N87 cells (Figure 7B), whereas knockdown of ARPP-19 inhibited sphere formation of NCI-N87-HR cells (Figure 7C). The expression of $A R P P-19$ was elevated in NCI-N87-derived sphere as compared to its parental NCI-N87 cells, at both mRNA and protein levels (Figure 7D and E). Taken together, these results suggested $A R P P-19$ regulated stemness in Herceptin resistant gastric cancer cells and this might be mediated by $C D 44$. 


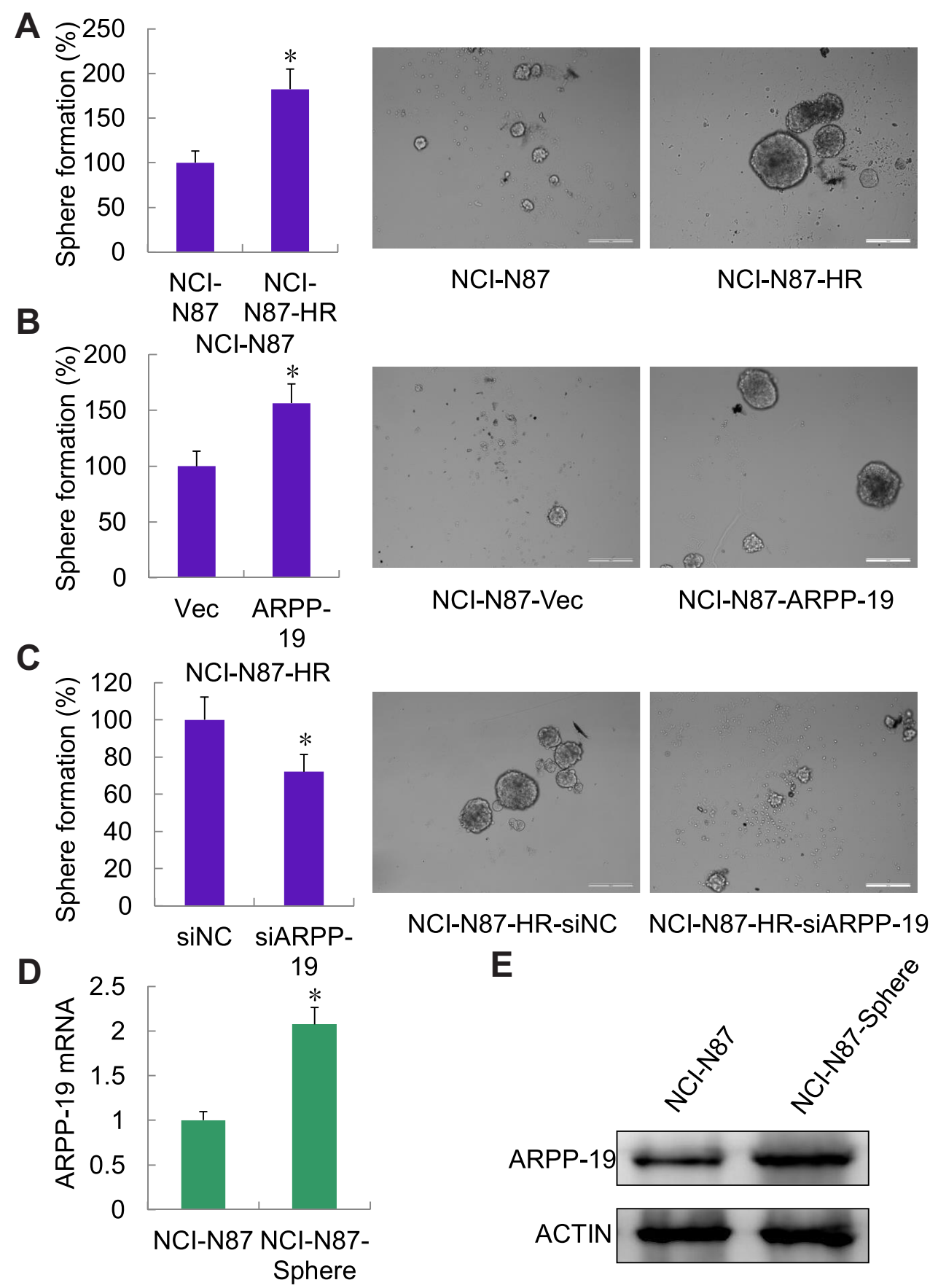

Figure 7 ARPP-19 mediated sphere formation of NCl-N87 cells. (A) Sphere formation was detected in NCl-N87-HR cells and its parental NCl-N87 cells. (B) Sphere formation was detected in NCl-N87 cells stably transfected with ARPP-19 overexpression plasmid (NCl-N87 ARPP-19) or empty vector (NCl-N87 Vec). (C) Sphere formation was detected in NCl-N87-HR cells transfected with siRNAs against ARPP-19 (siARPP-19) or negative control siRNA (siNC). (D and E) mRNA and protein levels of ARPP-19 in NCl-N87-HR cells and its parental NCl-N87 cells were determined by qRT-PCR and Western blot. $* P<0.05$.

ARPP-19 Was Associated with Herceptin Resistance and Poor Survival of HER2-Positive Gastric Cancer Patients

In further, 50 paraffin-embedded HER2-positive gastric cancer tissues were collected and protein levels of ARPP-19 and CD44 in these HER2-positive gastric cancer tissues were examined by IHC staining. ARPP19 and $C D 44$ were both up-regulated in gastric cancer tissues with Herceptin resistance as compared with Herceptin-sensitive gastric cancer tissues (Figure 8A). Elevated ARPP-19 was significantly positively associated with Herceptin resistance of gastric cancer 
A

ARPP-19

CD44
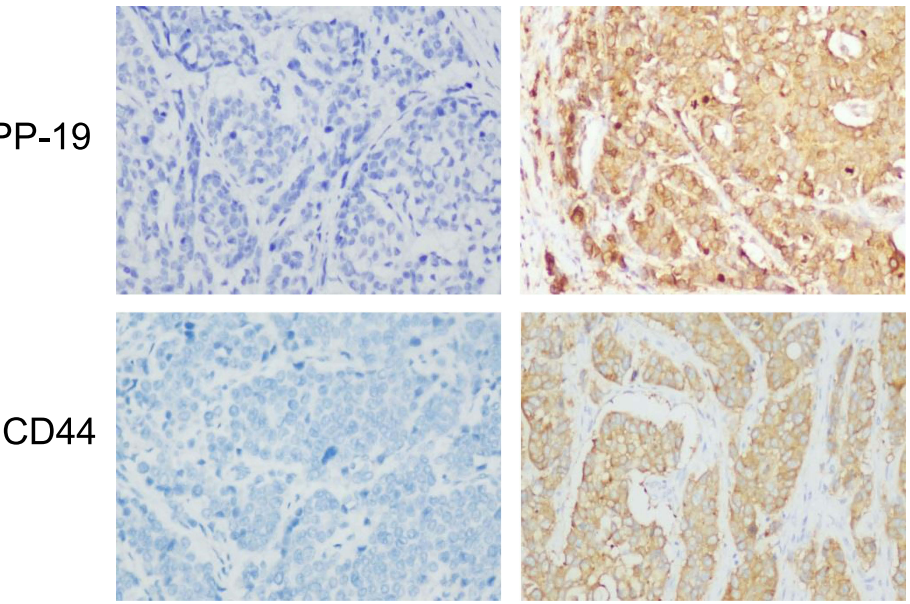

Herceptin Sensitive

GC tissue

Herceptin Resistant

GC tissue

B

\begin{tabular}{|c|c|c|c|}
\hline \multicolumn{2}{|c|}{ Expression of ARPP-19 in HER2 positive gastric cancer tissues } \\
\cline { 3 - 4 } Group & $\mathrm{n}$ & Low, $\mathrm{n}(\%)$ & High, $\mathrm{n}(\%)$ \\
\hline $\begin{array}{c}\text { Herceptin Sensitive GC } \\
\text { tissues }\end{array}$ & 29 & $19(65.52)$ & $10(34.48)$ \\
\hline $\begin{array}{c}\text { Herceptin Resistant GC } \\
\text { tissues }\end{array}$ & 21 & $6(28.57)$ & $15(71.43)$ \\
\hline$P=0.010$ & \multicolumn{3}{|c|}{} \\
\hline \multicolumn{3}{|l}{}
\end{tabular}

C

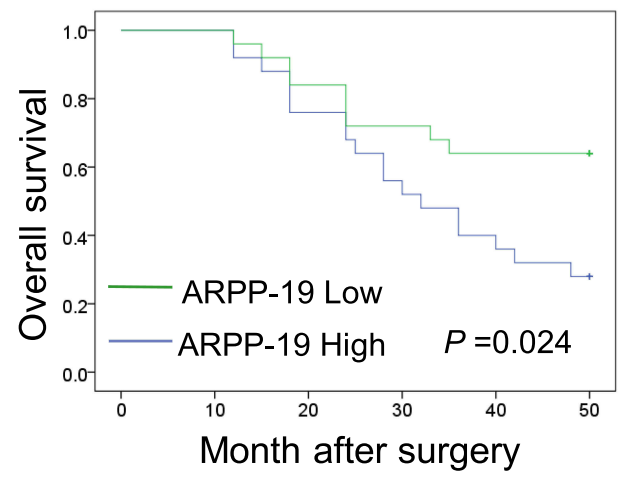

D

\begin{tabular}{|c|c|c|c|}
\hline \multicolumn{4}{|c|}{$\begin{array}{l}\text { Co-expression of ARPP-19 and CD44 in } \\
\text { HER2 positive gastric cancer tissues }\end{array}$} \\
\hline & & \multicolumn{2}{|c|}{ ARPP-19 protein } \\
\hline & & Low, n (\%) & High, n (\%) \\
\hline \multirow{2}{*}{$\begin{array}{l}\text { CD44 } \\
\text { protein }\end{array}$} & $\begin{array}{l}\text { Low, } \\
\mathrm{n}(\%)\end{array}$ & $18(36.0)$ & $5(10.0)$ \\
\hline & $\begin{array}{l}\text { High, } \\
\text { n (\%) }\end{array}$ & $7(14.0)$ & $20(40.0)$ \\
\hline
\end{tabular}

Figure 8 Increased ARPP-19 level in HER2-positive GC tissues predicted poor survival. (A) Representative images of IHC staining showed protein levels of ARPP-19 and CD44 in Herceptin-resistant GC tissues and Herceptin-sensitive GC tissues. (B) Chi-square analysis of ARPP-19 protein level in 21 Herceptin-resistant GC tissues and their 29 Herceptin-sensitive GC tissues. (C) The overall survival rates of HER2-positive gastric cancer patients with different ARPP-19 expression levels were analyzed by KaplanMeier curves. (D) Co-expression analysis of ARPP-19 and CD44 in HER2-positive GC tissues.

patients (Figure 8B). Besides, patients with high ARPP19 levels showed lower overall survival rate $(P=0.024)$ compared with patients with low ARPP-19 levels (Figure 8C). Moreover, Figure 8D shows that ARPP-19 and $C D 44$ were correlated in these 50 HER2-positive gastric cancer tissues. Taken together, elevated expression of ARPP-19 in HER2-positive gastric cancer predicted poor prognosis.

\section{Discussion}

In the current study, we comprehensively investigated the expression pattern, function and underlying mechanisms of ARPP-19 in Herceptin resistance of human HER2positive gastric cancer. Expression levels of $A R P P-19$ were elevated in HER2-positive gastric cancer cells and tissues with acquired Herceptin resistance, and prognosis study showed that patients with a higher expression level 
of ARPP-19 had a shorter overall survival rate. Functionally, silence of ARPP-19 decreased, while the forced expression of $A R P P-19$ promoted the Herceptin resistance of HER2-positive gastric cancer cells in vitro. Furthermore, overexpression of ARPP-19 increased the Herceptin resistance of MKN45 cells in xenograft model in vivo. Mechanically, $A R P P-19$ promoted the cancer stem properties by up-regulation of $C D 44$, a famous cancer stem cell marker in gastric cancer. ${ }^{27,28}$ In addition, depletion of $C D 44$ re-sensitized the Herceptin resistant gastric cancer cells to Herceptin, which indicated CD44 was also a positive regulator of Herceptin resistance in HER2positive gastric cancer. Thereby, this study expanded our understanding of ARPP-19 in HER2-positive gastric cancer with Herceptin resistance.

Recent studies reported that the expression of ARPP-19 was deregulated in hepatocellular carcinoma. ${ }^{17}$ Besides, $A R P P-19$ has also been reported to contribute to tumorigenesis and progression of glioma and acute myeloid leukemia. ${ }^{16,29}$ Moreover, it was also reported that $A R P P$ 19 , which was negatively regulated by $m i R-320 a$, promoted tamoxifen resistance of breast cancer cells. ${ }^{23}$ However, the functions and underlying mechanisms of ARPP-19 in gastric cancer and Herceptin resistance were poorly understood.

Tumors were heterogeneous and a small proportion of cells with stem cell features in tumor tissues was called cancer stem cell (CSCs), which was considered to contribute to tumor initiation. ${ }^{30,31} \mathrm{CSCs}$ were characterized with selfrenewal, resistance to treatment and high metastasis potential, all of which make them the source of cancer relapse and treatment failure. ${ }^{32,33}$ Especially, CSCs played crucial roles in cancers with acquired Herceptin resistance. ${ }^{26,34,35} \mathrm{We}$ herein demonstrated that $C D 44$ was regulated by ARPP-19 and mediated Herceptin resistance of human HER2-positive gastric cancer cells. Plenty of literatures demonstrated that CD44 played oncogenic roles in various human cancers, ${ }^{36-40}$ gastric cancer included. ${ }^{41-43}$ Furthermore, CD44 was a famous mediator to regulate cancer stem cell-like properties. As reported previously, Isorhapontigenin (ISO) inhibits stem cell-like properties and invasion of bladder cancer cell by attenuating CD44 expression. ${ }^{44}$ EGCG inhibits CSC-like properties through targeting miR-485/CD44 axis in A549cisplatin-resistant cells. ${ }^{45}$ LncRNA DGCR5 contributes to CSC-like properties via modulating $m i R-330-5 p / C D 44$ in NSCLC. ${ }^{46}$ In this study, we demonstrated ARPP-19 upregulated the expression of $C D 44$ and promoted sphere formation, which indicated the enhancement of cancer stem cell-like properties in gastric cancer cells. Therefore, we concluded ARPP-19 promoted Herceptin resistance of $H E R 2$-positive gastric cancer through regulation of $C D 44-$ mediated cancer stem cell-like properties. However, it still needs further study to clarify the specific molecular mechanisms on regulation of CD44 by ARPP-19.

In conclusion, we herein verified the functional roles and underlying molecular mechanisms of ARPP-19 in Herceptin resistance of human HER2-positive gastric cancer cells, and revealed the expression patterns and prognostic correlation of $A R P P-19$ in HER2-positive gastric cancer patients. ARPP-19 might thereby be a potential novel therapeutic target and diagnostic biomarker in human HER2-positive gastric cancer.

\section{Disclosure}

The authors declare that they have no conflicts of interest.

\section{References}

1. Bray F, Ferlay J, Soerjomataram I, Siegel RL, Torre LA, Jemal A. Global cancer statistics 2018: GLOBOCAN estimates of incidence and mortality worldwide for 36 cancers in 185 countries. CA-Cancer J Clin. 2018;68(6):394-424. doi:10.3322/caac.21492

2. Jiang YM, Li TJ, Liang XL, et al. Association of adjuvant chemotherapy with survival in patients with Stage II or III gastric cancer. JAMA Surg. 2017;152:7. doi:10.1001/jamasurg.2017.1087

3. Apicella M, Corso S, Giordano S. Targeted therapies for gastric cancer: failures and hopes from clinical trials. Oncotarget. 2017;8 (34):57654-57669. doi:10.18632/oncotarget.14825

4. He XX, Ding L, Lin Y, Shu M, Wen JM, Xue L. Protein expression of HER2, 3, 4 in gastric cancer: correlation with clinical features and survival. J Clin Pathol. 2015;68(5):374-380. doi:10.1136/jclinpath2014-202657

5. Gravalos C, Jimeno A. HER2 in gastric cancer: a new prognostic factor and a novel therapeutic target. Ann Oncol. 2008;19 (9):1523-1529. doi:10.1093/annonc/mdn169

6. Tanner M, Hollmen M, Junttila TT, et al. Amplification of HER-2 in gastric carcinoma: association with Topoisomerase II alpha gene amplification, intestinal type, poor prognosis and sensitivity to trastuzumab. Ann Oncol. 2005;16(2):273-278. doi:10.1093/annonc/ mdi064

7. Schneider MR, Yarden Y. The EGFR-HER2 module: a stem cell approach to understanding a prime target and driver of solid tumors. Oncogene. 2016;35(23):2949-2960. doi:10.1038/onc.2015. 372

8. Shi JL, Li FP, Yao XX, et al. The HER4-YAP1 axis promotes trastuzumab resistance in HER2-positive gastric cancer by inducing epithelial and mesenchymal transition. Oncogene. 2018;37(22): 3022-3038. doi:10.1038/s41388-018-0204-5

9. Eto K, Iwatsuki M, Watanabe $M$, et al. The sensitivity of gastric cancer to trastuzumab is regulated by the miR-223/FBXW7 pathway. Int J Cancer. 2015;136(7):1537-1545. doi:10.1002/ijc.29168

10. Tang LQ, Long ZG, Zhao N, Feng GJ, Guo XZ, Yu M. NES1/KLK10 promotes trastuzumab resistance via activation of PI3K/AKT signaling pathway in gastric cancer. $J$ Cell Biochem. 2018;119 (8):6398-6407. doi:10.1002/jcb.26562

11. Horiuchi A, Williams KR, Kurihara T, Nairn AC, Greengard P. Purification and cDNA cloning of ARPP-16, a cAMP-regulated phosphoprotein enriched in basal ganglia, and of a related phosphoprotein, ARPP-19. J Biol Chem. 1990;265(16):9476-9484. 
12. Dulubova I, Horiuchi A, Snyder GL, et al. ARPP-16/ARPP-19: a highly conserved family of cAMP-regulated phosphoproteins. J Neurochem. 2001;77(1):229-238. doi:10.1046/j.1471-4159.2001. t01-1-00191.x

13. Girault JA, Horiuchi A, Gustafson EL, Rosen NL, Greengard P. Differential expression of ARPP-16 and ARPP-19, 2 highly related camp-regulated phosphoproteins, one of which is specifically associated with dopamine-innervated brain-regions. J Neurosci. 1990;10 (4):1124-1133. doi:10.1523/JNEUROSCI.10-04-01124.1990

14. Irwin N, Chao S, Goritchenko L, et al. Nerve growth factor controls GAP-43 mRNA stability via the phosphoprotein ARPP-19. P Natl Acad Sci USA. 2002;99(19):12427-12431. doi:10.1073/pnas.152457399

15. Kim SH, Nairn AC, Cairns N, Lubec G. Decreased levels of ARPP19 and PKA in brains of Down syndrome and Alzheimer's disease. J Neural Transm-Supp. 2001;61:263-272.

16. Jiang T, Zhao B, Li XC, Wan JH. ARPP-19 promotes proliferation and metastasis of human glioma. Neuroreport. 2016;27(13):960-966. doi:10.1097/WNR.0000000000000638

17. Song HY, Pan JL, Liu Y, et al. Increased ARPP-19 expression is associated with hepatocellular carcinoma. Int J Mol Sci. 2015;16 (1):178-192. doi:10.3390/ijms16010178

18. Zuo Q, Liu J, Zhang JW, Wu MW, Guo LH, Liao WJ. Development of trastuzumab-resistant human gastric carcinoma cell lines and mechanisms of drug resistance. Sci Rep-Uk. 2015;5.

19. Zhang WJ, Wu MM, Chong QY, et al. Loss of estrogen-regulated MIR135A1 at 3p21.1 promotes tamoxifen resistance in breast cancer. Cancer Res. 2018;78(17):4915-4928. doi:10.1158/0008-5472.CAN18-0069

20. Tan S, Li H, Zhang WJ, et al. NUDT21 negatively regulates PSMB2 and CXXC5 by alternative polyadenylation and contributes to hepatocellular carcinoma suppression. Oncogene. 2018;37(35):48 87-4900. doi:10.1038/s41388-018-0280-6

21. Zhou XL, Men XY, Zhao RY, et al. miR-200c inhibits TGF-betainduced-EMT to restore trastuzumab sensitivity by targeting ZEB1 and ZEB2 in gastric cancer. Cancer Gene Ther. 2018;25(3-4):68-76. doi:10.1038/s41417-017-0005-y

22. Ding KH, Wu ZS, Wang NN, et al. MiR-26a performs converse roles in proliferation and metastasis of different gastric cancer cells via regulating of PTEN expression. Pathol Res Pract. 2017;213 (5):467-475. doi:10.1016/j.prp.2017.01.026

23. Lu MR, Ding KH, Zhang GF, et al. MicroRNA-320a sensitizes tamoxifen-resistant breast cancer cells to tamoxifen by targeting ARPP-19 and ERR gamma. Sci Rep-Uk. 2015;5.

24. Yu BQ, Chen XH, Li JF, et al. microRNA-29c inhibits cell proliferation by targeting NASP in human gastric cancer. BMC Cancer. $2017 ; 17$.

25. Zhou YR, Li RH, Yu HD, Wang RT, Shen ZQ. microRNA-130a is an oncomir suppressing the expression of CRMP4 in gastric cancer. Once Targets Ther. 2017;10.

26. Yang ZY, Guo L, Liu D, et al. Acquisition of resistance to trastuzumab in gastric cancer cells is associated with activation of IL-6/ STAT3/Jagged-1/Notch positive feedback loop. Oncotarget. 2015;6 (7):5072-5087. doi:10.18632/oncotarget.3241

27. Sohn SH, Kim B, Sul HJ, Choi BY, Kim HS, Zang DY. Foretinib inhibits cancer sternness and gastric cancer cell proliferation by decreasing CD44 and c-MET signaling. Once Targets Ther. 2020;13:1027-1035. doi:10.2147/OTT.S226951

28. Sun M, Zhou W, Zhang YY, Wang DL, Wu XL. CD44(+) gastric cancer cells with stemness properties are chemoradioresistant and highly invasive. Oncol Lett. 2013;5(6):1793-1798. doi:10.3892/ ol.2013.1272

29. Makela E, Loyttyniemi E, Salmenniemi U, et al. Arpp19 promotes Myc and Cip2a expression and associates with patient relapse in acute myeloid leukemia. Cancers. 2019;11(11):11. doi:10.3390/ cancers 11111774
30. Schulenburg A, Blatt K, Cerny-Reiterer S, et al. Cancer stem cells in basic science and in translational oncology: can we translate into clinical application? J Hematol Oncol. 2015;8.

31. Clarke MF, Dick JE, Dirks PB, et al. Cancer stem cells - perspectives on current status and future directions: AACR Workshop on cancer stem cells. Cancer Res. 2006;66(19):9339-9344. doi:10.1158/00085472.CAN-06-3126

32. Charafe-Jauffret E, Ginestier C, Iovino F, et al. Aldehyde dehydrogenase 1-positive cancer stem cells mediate metastasis and poor clinical outcome in inflammatory breast cancer. Clin Cancer Res. 2010;16(1):45-55. doi:10.1158/1078-0432.CCR-09-1630

33. Xu GH, Shen J, Yang XHO, Sasahara M, Su XL. Cancer stem cells: the 'heartbeat' of gastric cancer. $J$ Gastroenterol. 2013;48 (7):781-797. doi:10.1007/s00535-012-0712-y

34. Li YF, Chu JH, Feng WT, et al. EPHA5 mediates trastuzumab resistance in HER2-positive breast cancers through regulating cancer stem cell-like properties. FASEB J. 2019;33(4):4851-4865. doi:10.10 96/fj.201701561RRRR

35. Kim YJ, Sung D, Oh E, et al. Flubendazole overcomes trastuzumab resistance by targeting cancer stem-like properties and HER2 signaling in HER2-positive breast cancer. Cancer Lett. 2018;412:118-130. doi:10.1016/j.canlet.2017.10.020

36. Chen PC, Yu CC, Huang WY, et al. c-Myc acts as a competing endogenous RNA to sponge miR-34a, in the upregulation of CD44, in urothelial carcinoma. Cancers. 2019;11:10. doi:10.3390/cancers 11 101457

37. Pan SM, Liu YQ, Liu QQ, et al. HOTAIR/miR-326/FUT6 axis facilitates colorectal cancer progression through regulating fucosylation of CD44 via PI3K/AKT/mTOR pathway (vol 1866, pg 750, 2019). Bba-Mol Cell Res. 2019;1866(8):1353.

38. Chan LS, Man OY, Kwok HH, et al. The Wnt modulator ICG-001 mediates the inhibition of nasopharyngeal carcinoma cell migration in vitro via the miR-150/CD44 axis. Int $J$ Oncol. 2019;54 (3):1010-1020. doi:10.3892/ijo.2018.4664

39. Li XJ, He JY, Shao MM, et al. Downregulation of miR-218-5p promotes invasion of oral squamous cell carcinoma cells via activation of CD44-ROCK signaling. Biomedicine Pharmacother. 2018;106:646-654. doi:10.1016/j.biopha.2018.06.151

40. Al-Othman N, Hammad H, Ahram M. Dihydrotestosterone regulates expression of CD44 via miR-328-3p in triple-negative breast cancer cells. Gene. 2018;675:128-135. doi:10.1016/j.gene.2018.06.094

41. Mereiter S, Martins AM, Gomes C, et al. O-glycan truncation enhances cancer-related functions of CD44 in gastric cancer. FEBS Lett. 2019;593(13):1675-1689. doi:10.1002/1873-3468.13432

42. Hong YL, Qin HF, Li Y, et al. FNDC3B circular RNA promotes the migration and invasion of gastric cancer cells via the regulation of E-cadherin and CD44 expression. J Cell Physiol. 2019;234 (11):19895-19910. doi:10.1002/jcp.28588

43. Xiao WS, Li DF, Tang YP, et al. Inhibition of epithelial-mesenchymal transition in gastric cancer cells by miR-711-mediated downregulation of CD44 expression. Oncol Rep. 2018;40(5):2844-2853. doi:10.3892/or.2018.6681

44. Luo YS, Tian ZX, Hua XH, et al. Isorhapontigenin (ISO) inhibits stem cell-like properties and invasion of bladder cancer cell by attenuating CD44 expression. Cell Mol Life Sci. 2020;77 (2):351-363. doi:10.1007/s00018-019-03185-3

45. Jiang P, Xu CY, Chen LJ, et al. EGCG inhibits CSC-like properties through targeting miR-485/CD44 axis in A549-cisplatin resistant cells. Mol Carcinogen. 2018;57(12):1835-1844.

46. Wang R, Dong HX, Zeng J, Pan J, Jin XY. LncRNA DGCR5 contributes to CSC-like properties via modulating miR-330-5p/CD44 in NSCLC. J Cell Physiol. 2018;233(9):7447-7456. doi:10.1002/jcp.26 590 


\section{Publish your work in this journal}

OncoTargets and Therapy is an international, peer-reviewed, open access journal focusing on the pathological basis of all cancers, potential targets for therapy and treatment protocols employed to improve the management of cancer patients. The journal also focuses on the impact of management programs and new therapeutic agents and protocols on patient perspectives such as quality of life, adherence and satisfaction. The manuscript management system is completely online and includes a very quick and fair peer-review system, which is all easy to use. Visit http://www.dovepress.com/ testimonials.php to read real quotes from published authors.

Submit your manuscript here: https://www.dovepress.com/oncotargets-and-therapy-journal 